\title{
Growing pains of a genomics industry
}

Sir - Your report on Chinese genomics ventures is interesting and informative (Nature 394, 601-602; 1998; see also Briefing in this issue, page 303). Although this is clearly an exciting time for such activities in China, one could argue that, at present, the proposed commercialization of genomics may do more harm than good.

A business cannot be built out of a vacuum. Some of the initial requirements are a sophisticated financial infrastructure to support high-risk investment, a pharmaceutical industry strong enough to support start-up companies and form critical alliances, and a social culture that can tolerate the 'trial and error' nature of such start-ups. Also needed are an effective legal system for protecting intellectual property, the ability to develop new technology, and an advanced science base capable of making the discoveries that are essential to success.

China does not meet these conditions. For example, the research and development budget of an average US pharmaceutical company is about 20 per cent of revenue. But in China, most companies do not spend any money on research, as the drugs they produce are 'copies' of drugs developed elsewhere. Furthermore, the 1993 Chinese patent law implies that genes cannot be patented, while in genomics research there are only a few complementary DNA sequencing programmes, and positional cloning, genomic mapping and sequencing have yet to start.

Hastily launching a genomics industry in this environment is premature. But the process has already begun. Genomics is being over-promoted by academics, with promises that will not be kept, and without the necessary substantial budgetary support from the government. In industry, some ventures have already been set up with little understanding of the marketing or financial factors involved.

It may take many years for a start-up to reach profitability, and the premature loss of backing may curtail an otherwise successful venture. The recent setback to genomics ventures backed by real-estate concerns in Shanghai and Beijing illustrate this. Such quasi-commercial ventures do not only damage the reputation of the scientists and research institutions involved, they also confuse policy makers and private citizens, evoking an old Chinese saying that if you go too fast, you may not reach your destination.
Genomics does, however, present a significant opportunity for China to advance its biotechnology research. And the Chinese research community has shown much maturity in recent conferences and meetings, acknowledging that it will take consistent and persistent efforts to reach its goals. Some of the problems mentioned here reflect a common growing pain for the Chinese Human Genome Project which is still in its infancy.

Chinese leaders in research, administration and business should heed the lessons of the financial crisis in Asia, namely that a copy-cat economy is unsustainable without committed research and development efforts and the protection of intellectual property. The best way to achieve success in the industrialization of genomics is through long-term, focused investment, and sustained efforts to build a strong, internationally competitive research programme. For this goal, China needs dedicated genome scientists more than scientists-turned-entrepreneurs.

\section{G. Matthew Huang}

Pangea Systems Inc., 1999 Harrison Street, Suite 1100, Oakland, California 94612, USA, and National Human Genome Center, Shanghai, China

\section{Combat climate change by reducing fertility}

Sir - By treating future population as fixed, David Victor ${ }^{1}$ and M. I. Hoffert et al. ${ }^{2}$ frame the problem of stabilizing atmospheric $\mathrm{CO}_{2}$ as a wholly technological one. But policy-makers need to be aware of all the factors that can significantly reduce the energy demands they highlight.

The mid-range population projection employed $^{2}$ is chiefly dependent on the questionable assumption of replacementlevel fertility rate ( 2.1 births per woman) in the long run ${ }^{3}$. If policy options that improve social welfare shift that rate by less than half a birth per woman (to 1.7) — a rate above that in many industrialized countries - the projected population drops by $18 \%$ in 2050 and by $46 \%$ in 2100 (ref. 4). The total energy demand will drop by the same amount (by 5 TW and 20 TW respectively), considerably easing $\mathrm{CO}_{2}$ stabilization ${ }^{2}$.

Improvements in reproductive health, education and gender equality are desirable and also tend to reduce fertility ${ }^{3}$. It should interest policy-makers that accelerating them will also help stabilize climate.

Stuart R. Gaffin

Environmental Defense Fund, New York 10010, USA

\section{Brian C. O’Neill}

Brown University, Providence,

Rhode Island 02912, USA

1. Victor, D. G. Nature 395, 837-838 (1998).

2. Hoffert, M. I. et al. Nature 395, 881-884 (1998).

3. Bongaarts, J. Science 282, 419-420 (1998).

4. United Nations. World Population Projections to 2150(UN, 1998).

\section{Radical reform needed}

\section{to aid junior scientists}

Sir - The call to limit the number of PhD students at least acknowledges that there is a growing glut of junior scientists (Nature 395, $101 \& 103 ; 1998)$. It is, however, a futile gesture that fails to recognize that the glut is merely a symptom. The heart of the problem is how we recognize and reward the success of group leaders.

A group leader's apparent productivity is measured by the number and impact of the publications of their group. With more publications they can acquire more grant money. With this funding they can hire additional junior scientists to generate more publications. The oversupply and devaluation of postdoctoral scientists is the inevitable consequence. Symptoms of the same disease that drives the glut are nepotism and honorary authorship; blocking the grants or publications of competitors; the abuse of power; and even fraud.

How can we break the vicious cycle? One approach may be to change how we measure a group leader's performance. The funding system should measure the 'effectiveness' of group leaders by dividing their research performance by the effective size of their groups. Funding according to effectiveness would shift the selection pressure on groups from size to efficiency, and would allow small, efficient groups and even individuals to remain viable.

The current funding system permits group leaders to hold multiple grants which are used to employ junior investigators for specific projects. The system sanctions the erosion of the intellectual freedom of junior scientists and exposes them to abuses of power. These problems would be avoided if junior scientists were funded directly and could use this funding to apply to join existing research groups. A group's funding would then be determined, in part, by the number of junior scientists it could attract.

Young scientists deserve a better system. I urge the scientific community to consider these underlying problems seriously and to act soon on workable solutions.

\section{Gerard Vassiliou}

University of Ottawa Heart Institute, 40 Ruskin Street, Ottawa, Ontario K1Y 4W7, Canada 